\title{
LOWER BOUNDS FOR THE NUMERICAL RADIUS
}

\author{
HWA-LONG GAU AND PEI YuAN Wu
}

Abstract. We show that if $A=\left[a_{i j}\right]_{i, j=1}^{n}$ is an $n$-by- $n$ complex matrix and $A^{\prime}=\left[a_{i j}^{\prime}\right]_{i, j=1}^{n}$, where

$$
a_{i j}^{\prime}= \begin{cases}a_{i j} & \text { if }(i, j)=(1,2), \ldots,(n-1, n) \text { or }(n, 1), \\ 0 & \text { otherwise }\end{cases}
$$

then $w(A) \geqslant w\left(A^{\prime}\right)$, where $w(\cdot)$ denotes the numerical radius of a matrix. Moreover, if $n$ is odd and $a_{12}, \ldots, a_{n-1, n}, a_{n 1}$ are all nonzero, then $w(A)=w\left(A^{\prime}\right)$ if and only if $A=A^{\prime}$. For an even $n$, under the same nonzero assumption, we have $W(A)=W\left(A^{\prime}\right)$ if and only if $A=A^{\prime}$, where $W(\cdot)$ is the numerical range of a matrix.

Mathematics subject classification (2010): 15A60.

Keywords and phrases: Numerical range, numerical radius.

\section{REFERENCES}

[1] A. AbU-OMAR And P. Y. WU, Scalar approximants of quadratic operators with applications, preprint.

[2] M. Berger, Geometry I, Springer, Berlin, 1987.

[3] R. Bhatia, M. D. Chol And C. Davis, Comparing a matrix to its off-diagonal part, Oper. Theory Adv. Appl. 40 (1989), 151-164.

[4] H.-L. GAU AND P. Y. WU, Numerical radius of Hadamard product of matrices, Linear Algebra Appl. 504 (2016), 292-308.

[5] H.-L. GAU AND P. Y. WU, Crawford numbers of companion matrices, Oper. Matrices 10 (2016), 863-880.

[6] R. A. Horn And C. R. Johnson, Topics in Matrix Analysis, Cambridge University Press, Cambridge, 1991.

[7] R. A. Horn And C. R. Johnson, Matrix Analysis, 2nd ed., Cambridge University Press, Cambridge, 2013.

[8] C.-K. LI, B.-S. TAM AND P. Y. Wu, The numerical range of a nonnegative matrix, Linear Algebra Appl. 350 (2002), 1-23.

[9] W. V. PARKER, Sets of complex numbers associated with a matrix, Duck Math. J. 15 (1948), 711-715.

[10] G. Polya And G. SZEgÖ, Problems and Theorems in Analysis, Vol. II, Springer, Berlin, 1976.

[11] M.-C. Tsai And P. Y. Wu, Numerical ranges of weighted shift matrices, Linear Algebra Appl. 435 (2011), 243-254. 